Transforming human trafficking rescue services in Nigeria: towards context specific intersectionality and traumainformed perspectives

\begin{tabular}{|r|l|}
\hline Journal: & Journal of Services Marketing \\
\hline Manuscript ID & JSM-07-2020-0290.R3 \\
\hline Manuscript Type: & Article \\
\hline Keywords: & Transformative, Gender, Culture \\
\hline \multicolumn{2}{l}{} \\
\end{tabular}

SCHOLARONE $^{\text {m }}$

Manuscripts 


\title{
Transforming human trafficking rescue services in Nigeria: towards context specific intersectionality and trauma-informed perspectives
}

\begin{abstract}
Purpose: This study introduces context-specific intersectionality and trauma-informed perspectives for transformative services theory and practice. While TSR research concerning vulnerable people has focused on well-being and alleviating suffering, there has been less attention paid to how the intersection of scales of social categorisation such as class, gender and cultural norms shape experiences and outcomes. Likewise, there is a paucity of attention to how lived experiences of trauma among people such as human trafficking survivors, can and should influence service interactions, delivery and outcomes.
\end{abstract}

Design/Methodology/Approach: We draw upon insights from a focused ethnographic study featuring narrative interviews with ten human trafficking survivors and seven rescue service industry stakeholders, as well as field observations, in Nigeria. Thus this work enriches the limited scholarship on transformative services across Africa, where local cultural contexts have a significant influence on shaping service environments.

Findings: We identify how the intersections of socio-economic class, gender dynamics, cultural norms, and trauma shape the service experience for survivors.

Originality/Value: We argue for the criticality of intersectionality and trauma-informed perspectives to transformative services in order to improve the mental and economic wellbeing of survivors of human trafficking in the long-term.

Keywords: TSR, human trafficking, modern slavery, intersectionality, class, gender, culture, trauma, Nigeria, Africa 


\section{Transforming human trafficking rescue services in Nigeria: towards context specific intersectionality and trauma-informed perspectives}

\section{Introduction}

Through a critical account of human trafficking in Nigeria, this paper argues that context-specific intersectionality and trauma approaches should inform transformative services. In doing so we build upon existing conversations in the services marketing literature regarding human trafficking (Loomba, 2017) and draw forth associations between transformative services (Rosenbaum et al., 2007), the intersectionality of class, gender and culture (Corus and Saatcioglu, 2015; Fisk et al., 2018), and trauma (Cheung and McCollKennedy, 2019). At the same time, we expand transformative service research (TSR) into the under-examined African context specifically in relation to both the lived experience of human trafficking survivors in Nigeria and the perspectives of service providers. A critical understanding of transformational services for vulnerable people such as human trafficking survivors is crucial not least in that human trafficking has harmful social and health consequences for millions of people worldwide (Ikeora, 2016; United Nations Office on Drugs and Crime [UNODC], 2018).

A form of modern slavery, human trafficking is the third most lucrative illicit trade in the world after arms and drug trafficking and is estimated to generate annually some US\$150 billion in illicit profits (International Labour Organization [ILO], 2017 ). Virtually every country in the world is affected by human trafficking either as a source, transit, or destination country (UNODC, 2018). An estimated 40 million people are victims of human trafficking (ILO, 2017) with women and girls accounting for 71 percent of this total (Minderoo Foundation's Walk Free Initiative, 2018). Human trafficking causes significant economic harms and is linked to considerable physical and mental health issues and social harms such 
as ostracism and stigmatisation of those trafficked and their families (Danailova-Trainor and Laczko, 2010; Oke, Lanre-Babalola and Tom, 2018). In Nigeria, human trafficking is multidimensional comprising international trafficking for the purpose of sex and labour exploitation, domestic trafficking for the purpose of sex and/or domestic servitude, and hazardous child labour (ILO, 2017).

Recently, human trafficking has attracted attention from marketing researchers (Pennington et al., 2009; Loomba, 2017). According to Pennington et al. (2009) human trafficking can be conceptualised as a marketing system in which the commodification of human beings, profit generation, services, distribution, and pricing systems are key components. Human trafficking is an important concern for TSR in terms of the foundational relationship between service and well-being, as survivors interact with services that provide rescue, food and shelter, psychological counselling, rehabilitation, and education and skills training (Loomba, 2017). In offering a transformative service-based model for human trafficking, Loomba (2017) acknowledges the critiques of existing human trafficking rescue services (see also for example Badéjọ et al., 2019) and argues for such services to focus on the re-establishment of community ties and restoring human dignity.

Building on this work, we draw attention to how intersectionality and trauma shape the experiences of service users and in turn should inform a transformative services approach to dealing with the effects of human trafficking. While TSR emphasises the co-creation of value through service exchanges that leads to consumer well-being (Rosenbaum et al., 2007; Anderson et al., 2011), ideas on how factors of intersectionality-class, gender, culture, and ideology — and understandings of trauma shape the transformative service environment are still emerging. This nascent TSR research attends to how race, class and gender dynamics can influence negative outcomes in services contexts such as healthcare (Corus and Saatcioglu, 2015). TSR research has also identified how ethnicity and gender influences consumer 
responses to service failures (Wu et al., 2016), and how cultural practices are important in shaping TSR related well-being outcomes (Hepi et al., 2017; Rosenbaum et al., 2018). Our research contributes to these emerging emphases on intersectionality in service research in particular in relation to under-studied, highly vulnerable service users, and non-Western contexts.

While TSR work concerning vulnerable groups such as refugees and asylum seekers has drawn attention to how human suffering may be alleviated by adopting a transformative services approach to bring about positive social change (Cheung and McColl-Kennedy, 2019; Nasr and Fisk, 2019), we extend this understanding through attending to trauma and traumainformed approaches (Poole and Greaves, 2012) as an important area of focus for transformative services. Specifically, our research explores how the intersections of socioeconomic class, gender, and Nigerian cultural norms, beliefs and practices, along with trauma experienced by survivors, shape human trafficking services and the service experience. In doing so we make the case for the adoption of intersectionality and trauma-informed approaches to transformative services to tackle complex social issues such as human trafficking.

Our article commences by introducing TSR and considers ideas on intersectionality, and trauma within the field. We then present our research context focusing on human trafficking in Nigeria, via a short background section, as an important social issue for TSR research. We next present our study methodology utilising a focused ethnography research design, before sharing our research findings. Our discussion and conclusions focus on the conceptual, empirical, and practical implications emerging from our inquiry, and suggest directions for future research and service implementation in this space. 


\section{Literature review and theoretical framework}

\section{Intersectionality in TSR}

TSR has been defined as "the integration of consumer and service research that centers on creating uplifting changes and improvements in the well-being of individuals (consumers and employees), families, social networks, communities, cities, nations, collectives, and ecosystems" (Anderson et al., 2011, p3). Accordingly, TSR focuses on how services can increase or decrease well-being, and considers issues including physical and mental health, financial well-being, discrimination, marginalisation, rehabilitation, and capacity building (Rosenbaum et al., 2011; Anderson and Ostrom, 2015). TSR is beginning to be applied to a wide variety of research contexts including healthcare (Danaher and Gallan, 2016), financial services (Mende and van Doorn, 2015), natural disaster recovery (Cheung et al., 2017), counselling and drug and alcohol services (Hepi et al., 2017), refugees and asylum seekers (Kabadayi, 2019; Cheung and McColl-Kennedy, 2019; Nasr and Fisk, 2019), and also human trafficking (Loomba, 2017). A major focus in TSR is on how service organisations can co-create value with consumers, leading to well-being.

The service marketing literature demonstrates an emerging focus on intersectionality to acknowledge how factors such as class, gender, and cultural background intersect in service environments to marginalise, harm, or restrict the well-being of consumers (Macdonald and Merrill, 2009; Corus and Saatcioglu, 2015). Services marketers have examined marginalisation, discrimination and exclusion in the service domain based on gender (Wu et al., 2016), culture and ethnicity (Hepi et al., 2017; Rosenbaum et al., 2018), age (Tomazelli et al., 2017), and sexuality (Minton et al., 2017). This work has helped identify how the intersection of class, race, and gender, for example, creates negative outcomes in service contexts and has triggered a call for a focus on intersectionality for TSR (Corus and Saatcioglu, 2015). As one example of this, in an experimental study on US 
consumer responses to management level service failures, Wu et al. (2016) found that Hispanic female managers experienced ethnic and gender stereotyping and significantly higher levels of negative consumer responses.

However, there is a paucity of research that has considered how intersectionality is associated with power relations, disadvantages, access, encounters, and consumer well-being in the service domain (Corus and Saatciioglu 2015). Nor has service research paid much attention to these issues in contexts in which socially unacceptable services such as human trafficking (see Rosenbaum and Russell-Bennett, 2020) compete with rescue services. There is also less focus on the ways that intersections of class, gender and cultural factors shape how value is perceived, created or even destroyed, and the resultant effects on objective and subjective well-being in TSR environments. Research in these areas will be important for informing how we can adopt intersectionality informed approaches to TSR in practice (Dietrich et al., 2017), especially in contexts in which trauma is another important factor such as in the case of human trafficking in Nigeria. This is important if TSR wishes to achieve the aim of preventing stigma, discrimination, and oppression and succeed in creating inclusive service systems by 2050 (Fisk et al., 2018). Furthermore, there is an urgent need for the application of context-specific, and non-Western understandings intersectionality and its constituent factors.

Intersectionality is a conceptual framework for understanding how elements of a person's demographic, social and political characteristics such as class, gender, race and ethnicity, culture, sexuality, ability, physical appearance, or political beliefs might intersect to produce and reproduce unique modes of privilege or oppression (Davis, 1981; Crenshaw, 1989; McCall, 2005). As Crenshaw (1989, p149) explains:

Discrimination, like traffic through an intersection, may flow in one direction and it may flow in another. If an accident happens at an intersection, it can be caused by 
cars travelling from any number of directions and, sometimes, from all of them.

Similarly, if a black woman is harmed because she is in the intersection, her injury could result from sex discrimination or race discrimination.

Further, "intersectionality is a lens through which you can see where power comes and collides, where it interlocks and intersects" (Crenshaw, 2019, pX). Human trafficking is a context in which the intersectionality of class, gender and culture is at the fore, though these dynamics are often downplayed (Valadier, 2018; Ibezim-Ohaeri, 2018). For example, the dominant binary discourse on human trafficking, particularly in/for sex work, constructs trafficked individuals either as rational economic actors, in which case sex work is considered legitimate (see O'Brien et al., 2013), or as commodified victims according to the abolitionist feminist perspective (Jeffries, 1997; Mackay, 2014).

Importantly, as articulated by African feminists (see Imam, 2016), intersectionality takes on different forms on the continent as compared to in the West. Race plays less of a role than class, gender, ethnicity, and culture, that are all related to power dynamics within most African countries that have majority black populations (Ampofo et al, 2004). For example, issues relating to poverty, low-incomes, unemployment, and lack of good job and educational opportunities create class conditions in which some Nigerian women are susceptible to trafficking (Atong et al., 2018). Furthermore, pre-colonial African societies were organised based on seniority not gender, and equal status between women and men was afforded (Oyéwumi, 1997). Contemporary gender relations in Nigeria have been more shaped by the effects of colonialism, post-colonialism, and capitalism than tradition (Oluwọlé, 2014). In contrast to the traditional egalitarian gender history of what is now Nigeria, gender dynamics under capitalism in contemporary Nigeria serve to commodify and objectify women including their bodies, frame them as seeking wealth and being greedy, and expose them to risk of gender-based violence (Ogundipẹ́, 1994; Omorodion, 2009). 
Cultural beliefs in the supernatural (e.g. 'juju') intersect with class and gender in Nigeria. These beliefs have become embedded in rituals conducted by a witch doctor during which trafficked women swear an oath they perceive to be binding, not to divulge the identities of their traffickers and to pay back in full their debts for items accrued such as passports, flights, accommodation, and food (Ikeora, 2016; Baarda, 2016). These beliefs encourage us to consider intersectionalities that are distinct from Western perspectives, as evident in countries like Nigeria. Nigerian feminist scholars argue for a distinct consciousness of class, and gender, culture and socio-historic conditions in the struggle for the emancipation of women in the country (Madunagu, 2008). Accordingly, we argue that there is a need for existing human trafficking rescue services to adopt a transformative framework, acknowledge emic intersectionalities, and engage with trauma-informed approaches (Loomba, 2017; Badejo et al., 2019).

\section{A trauma-informed approach to TSR}

While TSR research has primarily focused on improving well-being, there is also a stream of work focusing on consumer vulnerability and alleviating human suffering (Kabadayi, 2019; Cheung and McColl-Kennedy, 2019; Nasr and Fisk, 2019). Our empirical data demonstrates that this is an important turn for TSR research. We posit that attempts to bring about positive social outcomes and well-being in contexts such as human trafficking should begin with an understanding of the traumatic lived experiences of participants. Human trafficking survivors often have experiences of being tricked and manipulated, sexually objectified, physically and sexually abused, and ostracised and stigmatised by their families, local communities and in society (Elabor-Idemudia, 2003; Omorodion, 2009; Oke et al., 2018). 
We seek to advance this agenda, by calling for the adoption of a trauma-informed approach to TSR alongside context-specific intersectional approaches. A trauma-informed approach can be understood as a program, organization, service, or service system that realises signs and symptoms, and considerable impact, that trauma has and understands potential paths for recovery (Poole and Greaves, 2012). A trauma informed TSR approach would integrate knowledge about trauma into policies, procedures, and practices; and seek to actively resist re-traumatization (Rubenstein et al., 2018). Elliot et al. (2005) propose that trauma-informed approaches operate according to six principles: safety; trustworthiness and transparency; peer support; collaboration and mutuality; empowerment voice and choice; and cultural, historical and gender issues.

However, Funston (2019) critiques the trauma-informed literature for its primary focus on biomedical and psychiatric factors that can serve to responsibilise, blame and pathologise the individual. Trauma-informed perspectives currently fail to acknowledge broader structural and cultural factors, and how intersectionalities of class, neoliberalism, gender, culture, race, and colonialism act as important vectors for trauma (Funston, 2019). Furthermore, trauma-informed approaches have been critiqued for being too abstract and open to interpretation, and lacking in practical relevance (Berliner and Kolko, 2016) suggesting that significant work is required to guide trauma-informed service delivery.

For services in contexts such as human trafficking adopting a trauma-informed approach would mean acknowledging the interrelation between trauma and symptoms of trauma such as substance abuse and depression, and working in collaboration with survivors, their family and friends and other relevant service agencies in a way that empowers survivors and consumers (Elliott et al., 2005). Crucially, as exemplified in our empirical data, subjective experiences of trauma are informed by class, gender, and culture. Through our ethnographic study with survivors and key stakeholders in Nigeria, we explore how 
intersectionality together with a trauma-informed approach can significantly enrich understandings of human trafficking rescue services and survivors, and inform a transformative future.

\section{Methodology}

\section{Approach}

As befits our focus on understanding the lived experiences of human trafficking survivors' interactions with the rescue service industry, and the perspectives of key stakeholders within the rescue industry, with a view to transforming service provision, we adopted a short-term ethnography research design. In doing so we harness the potential of ethnographic methods as a rigorous and relevant approach for qualitative service research (von Koskull, 2020). Specifically, as Pink and Morgan (2013) amply demonstrate, the intensities that characterise short-term ethnography are conducive to gaining rich and valid knowledge, just as this approach is of particular use in research which seeks to make interventions. Our short-term ethnography is substantially strengthened in that the lead researcher is a Nigerian born and raised woman, who is fluent in English, Nigerian Pidgin, and Yorùbá. She travelled to and resided in Lagos, Benin and Abuja, Nigeria for a period of several months to conduct the research. This helped to facilitate the development of trust and rapport with research participants and a more emic perspective to be represented.

The data presented in this paper was gathered through a combination of interviews with ten women located in a human trafficking rescue shelter in Lagos, Nigeria; and seven interviews with stakeholders from the rescue industry - representing a government agency for preventing human trafficking (the main provider of rescue services in Nigeria) and a human trafficking non-governmental organisation (NGO). This was supplemented by observations and fieldnotes collected by the lead researcher during all interviews, and more 
generally while residing in low-income neighbourhoods in Nigeria that are subject to high levels of human trafficking. These observations concerned poverty, lack of infrastructure and job opportunities, gender discourse, and cultural beliefs.

\section{Data collection}

All interviews adopted a narrative approach (Czarniawska, 2004). For the interviews with human trafficking survivors the lead researcher and a research assistant visited a human trafficking rescue shelter in Lagos that provides services such as counselling, rehabilitation, and reintegration support for trafficked persons. Interviews were conducted in Nigerian Pidgin English with 10 women who had been trafficked. Small sample sizes are common and valid in research on the lived experiences of participants, particularly in studies involving vulnerable groups and in which access may be limited (Adler and Adler, 2012). Interview participants were all female and between 18-29 years of age. Five had been rescued from internal trafficking, four from cross-border trafficking, and one in the process of being trafficked. Informed consent was obtained from each participant prior to the interview commencing. The (male) psychologist working at the rescue shelter provided additional information about the research to help participants make an informed decision about participating in the study.

The intent in the interviews with human trafficking survivors was to privilege their voices (a central dimension of trauma-informed approaches), and accordingly participants largely set the course of the dialogue (Thompson et al., 1989). This approach is holistic and seeks to provide a descriptive and thematic account of the subjective lived experiences of participants and relate these to each other, and to the overall macro-social context (Askegaard and Linnet, 2011). As such, the opening question for the interviews was simply: "Tell me your story, from the beginning to how you ended up here." No further a priori questions were 
used. Rather, the focus was on eliciting participant narratives about their lived experience of being trafficked and engaging with rescue services.

Respect for the storytellers is an important aspect of research with vulnerable populations. The interviewer resisted asking 'why' questions in order to avoid shifting the focus of the dialogue away from describing the experience as it was lived to a more distant and abstract discussion (Thompson, et al., 1989). Moreover, 'why' questions can be perceived as requests for rationalisation and can engender feelings of prejudgement and elicit defensive responses (Argyris, 1982). Because interviews with vulnerable groups can sometimes trigger powerful memories for participants, the shelter psychologist was also available to provide moral support and intervene if necessary. The interviews thus provided the participants an opportunity to express their own perceptions of their life experiences in their own terms (Gay and Hatton, 2000).

Interviews were also conducted with participants working for a government agency for preventing human trafficking (three in Lagos and one in Abuja), and a leading human trafficking NGO located in Benin City. Informed consent was obtained from each participant, and these interviews also followed a narrative approach in recognition of the importance of acknowledging their stories about front-line service provision in a traumatic context. Interviewees largely set the course of the dialogue with the researcher probing for deeper insights concerning the context of human trafficking in Nigeria.

We have protected participant identities by using pseudonyms. All interviews, participant responses and observable body language were transcribed verbatim (Kvale, 1983), other than correcting for grammar and tenses to improve clarity and understanding. Responses in Nigerian Pidgin English were translated into Standard English. The researcher's interview transcripts were checked against the research assistant's notes taken during interviews for accuracy prior to the commencement of coding of emerging themes using 
participants' own words. Interviews lasted between 30 and 90 minutes, were audio recorded, and transcribed by the lead researcher. The participant sample composition and a brief description of each participant is presented in Table I.

\section{INSERT TABLE Ia and Ib HERE}

\section{Analysis}

Our research adopted a grounded theory approach (Bryant and Charmaz, 2007) and was not conducted with an a priori theoretical framework guiding and our analysis and interpretation. Rather our context-specific intersectional and trauma-informed theoretical framework emerged from analysis and interpretation of the data. The first step in the analysis process involved searching for thematic insights using participants' own words in accordance with a grounded theory and emic approach (Kvale 1983). These themes were then coded with the assistance of qualitative data management software NVivo 10. During this coding process we identified dimensions of intersectionality: socio-economic class, gender and cultural norms, as applicable in the Nigerian context. We sought also to develop a nuanced understanding of participants' experiences alert to the ways in which these dimensions and experiences of trauma play out in individual narratives (Thompson, et al., 1989; Giesler and Thompson, 2016).

During this process, ethnographic observations and field notes were used to supplement the thematic interpretations that emerged from the interview data to provide context. Adopting an iterative and reflexive approach, we developed a collective interpretation and representation of meaning from the data. Our findings present interview extracts and draw on observation data to illustrate how intersections of class, gender, and culture in Nigeria and trauma shape the lived experiences of human trafficking survivors, and 
contrast with the delivery of rescue services. Given that intersectional trajectories are conceptualised as "accidents happen[ing] at an intersection" (Crenshaw 1989, p. 149) we present interview data through vignettes, in turn, respectful of the personal voices of vulnerable participants. Before doing so, we offer important background on our research context of human-trafficking services in Nigeria.

\section{Research context: Human trafficking in Nigeria}

Human trafficking rescue services in Nigeria are provided centrally by the Federal Government funded National Agency for the Prohibition of Trafficking In Persons and other related matters (NAPTIP) with offices in each of the 36 states of Nigeria. The agency is supported by a coalition of non-government organisations and charity-based providers subject to regulation by the Nigerian government. However, the extent to which these charity organisations are monitored and regulated is not known. Importantly, these rescue services must operate within an unusual competitive market system conceptualised by Rosenbaum and Russell-Bennett (2020) as 'socially unacceptable services' in which buyers and sellers enter socially unacceptable exchanges with the aim of obtaining value from these exchanges notwithstanding its illegality.

It is within this challenging context that Damilare, a Regional Head with a Government Human Trafficking Agency in Lagos, explained the services provided by his agency.

We rescue victims of human trafficking whether internal or external. Once they are rescued and brought here, we have a shelter where they are kept. It's a home built for us by the government where victims of human trafficking are kept at the first instance. A temporary place of abode so it's not permanent. Once they are taken to the shelter, we have professional trained counsellors, we have nurses, matrons, everybody 
responsible for them there in a homely environment. So, the first thing they do is counsel them in order to remove the traumatic experience they went through in the hands of the traffickers, so they get counselling for a period of time. Once they finished counselling, they move on to the next stage of rehabilitation. In this second stage of rehabilitation, they are introduced to informal education, vocational training like hair dressing, dressmaking, and other vocational skills in order to determine their interest. The vocational training is voluntary. Once any of them is identified to be interested in a particular vocational skill such a person is taken from our shelter to one of our partners where they will go for training until the stage of proficiency or become professionals in that field and then they are brought back to us for empowerment. Empowerment is the stage where we provide for them all the equipment they need to start life afresh, so they are empowered and as the rehabilitation is going on, we do what we call family tracing.

This suggests a good level of resources and at first appears to align with a TSR approach to tackling human trafficking (Loomba, 2017). However, when the lead researcher and research assistant visited a rescue shelter for trafficked women in a large coastal city in Nigeria where the interviews took place, they observed the challenges with lack of funding and capacity that these services experience. As described in our field notes:

The shelter was a decent looking albeit aging two-story apartment style complex on the far end of a remote estate in the city. The shelter looked moderately homey and comfortable from the outside. Inside the complex was a different story. The spaces felt dark and claustrophobic, lacking in both hope and basic necessities. The air was fraught with tension, the spaces dark, depressing, and ill-equipped, from the small open plan office space where the shelter administration staff sat with a glum 
expression, to the virtually unfurnished hall where residents gathered daily for group activities. The spaces were poorly ventilated, and furnishings were sparse and threadbare. Bathroom facilities lacked basic amenities including running water and toilet paper. Most shelter staff looked overworked and weary.

While providing valuable and important services to support human trafficking survivors, the shelter did not appear to create a wholly welcoming place for the delivery of transformative services to survivors but instead engenders a somewhat stark service environment that could create value destruction (Zainuddin and Gordon, 2020). The state of the shelter is reflective of community members account of the tensions inherent in Nigerian capitalism and how "those that have money in Nigeria, they don't help" (Field note, Lagos).

Despite being Africa's biggest economy, neoliberal capitalism in Nigeria has been severely criticised due to its associations with political instability and corruption, mass privatisation, endemic poverty, poor public health outcomes, a lack of jobs and liveable income, poor infrastructure such as electricity, roads, and water and sewerage, and restricted access to quality education (Ekanade, 2014; Abegunde and Akinyemi, 2014; Okpanachi and Obutte, 2015; Egharevba, Imhonopi and Iruonagbe, 2015). These conditions in Nigeria have made vulnerable groups such as low socio-economic status women vulnerable to the human trafficking system (Atong et al., 2018). Capitalistic cultural tropes regarding money, agency, status, achievement and success in Nigeria present human trafficking as a form of exchange relations that apparently offer a way for vulnerable women to escape class, gender and cultural oppression (Osezua, 2011). 


\section{FINDINGS}

For several participants, class conditions were an important factor in their experience of human trafficking. For many, this was considered an economic opportunity, a welcomed alternative to being unemployed in Nigeria. Itohan, a 28-year-old Bini woman reflects the class conditions driving the marketing system of human trafficking. She described how she found human trafficking economically empowering and her involuntary rescue disempowering. Itohan had a friend who had told her about an "opportunity" to travel for work. In Itohan's words:

It was the only opportunity I saw to make money so I can open my business... if I had made money, my money, I would have been happy, and I would use the money to support my business. I regret going there and coming back with empty hands...My first week working on my own, the police caught me...the police asked me for my Emirates ID...but since I am not a legal resident, they had to take me to the police station. From the police station, they took me to immigration. At the immigration, I was in jail for one month and three weeks. I was happy that I travelled out, but I came back with deporting, it's not good.

Itohan mentions a desire to make money several times in her account, demonstrating how economic conditions under Nigerian capitalism drive low socio-economic class women into the human trafficking system. Itohan seemed bitter about what she also perceived to be the injustice of her situation - she had been deported after just six months working as a prostitute in Dubai to repay her debt bondage. Itohan's sorrow at being suddenly and involuntarily rescued was palpable. However, Itohan also disclosed that she had felt bad about her sex work in Dubai: 
I was thinking this kind of business I'm doing is very bad. Sometimes I pray that if I have money or if I have somebody that will help me to pay then so that I will go out from here then look for some other business because there I know how to make hair. I'm a stylist.

Itohan's guilt and shame clashes with the rational economic choice discourse on sex work (O’Brien et al., 2013) and demonstrates how a supposed escape from economic oppression brings other forms of oppression (Oke et al., 2018). The unreflexive behaviour of male customers in the system also emerge through Itohan's story about how she had spoken "to one Arab man. He's from Iran. The man said my visa has already expired, he can only help me and can take me to a stylist so that I will be working, and they would be paying me salary. I said ok, before the policeman catch me". The intersectional dynamics here of class and gender create a sad irony in how male sex customers who create demand in the system and hold power (Pennington et al., 2009), make offers to 'rescue' women like Itohan from a system they help create.

Chika, a 27-year-old Igbo woman explained how she was unemployed, uneducated, and lived at home with her family upon whom she was entirely financially dependent prior to her being trafficked to Dubai. Chika explained that human trafficking was an acceptable alternative to being entirely dependent on relatives and would allow her to take control of her situation.

\footnotetext{
I knew what I was going to do, and I decided to go. I had nothing doing back home. I accepted and I was ok with prostitution because it is better than staying at home doing nothing. I don't work, it's only my sister that works. She feeds me, clothes me, so instead of only being able to say thank you sis, thank you sis, I need to help myself.
} 
For Chika, her low socio-economic status, lack of education and dependence on family made her vulnerable to entering the marketing system of human trafficking, just as it led her to view being trafficked as a rational economic choice. Her body language and tone of voice seemed defeated; she appeared resigned to her reality and hopeless, convinced that she had no other options at home. Her class oppression also becomes gendered through her seeming acceptance of the commodification of herself and her body through prostitution. Commodification of women's bodies becomes part of the market logic (Loomba, 2017). Chika viewed being trafficked as giving her agency and enabling her to help herself. She tearfully shared her tale of being involuntary rescued by human trafficking rescue services and wept at the injustice of being arrested on the eve of her becoming a free agent in Dubai, because it meant her years in debt bondage had all been for nothing. Her involuntary rescue had effectively eliminated her big chance at being economically empowered.

I wish I had made it I would have been so happy because my madam herself has made it. She has built a house you know...I wanted to do it for me too. I believed that I will make it. I wanted to make it in life. I was looking for a solution to help myself so that I am not sitting at home doing nothing

We see here that for Chika, being trafficked offers hope of a better life, higher income, and a cosmopolitan lifestyle in the city or overseas, compared to being stuck at home with nothing to do and no money. Furthermore, Chika is suggestive of misalignment in expectations about the human trafficking rescue service experience and her trauma at being rescued identifies how being engaged by rescue services can lead to value destruction (Anderson and Ostrom, 2015). 
Our interviewed survivors often shared tales of being arrested and then involuntarily removed from the human trafficking system. On the other hand, stakeholders from the rescue industry perceived that they are rescuing and saving women. The intersection of class, gender and power, demonstrated in Itohan and Chika's narratives of being 'involuntarily rescued,' appeared not to be acknowledged within the service environment. Johnson, a project officer with a human trafficking NGO providing support services in Benin City argued that the problem is being driven by "this get rich quick attitude that has become common in our society where everybody wants to make it no matter how it's the trend now. Belying his earlier positive account of the services provided to survivors, Damilare opined that:

\begin{abstract}
Greed is still a major factor in trafficking and greed in the sense that people think their story will be different. It's not a development issue. When you talk about development, you talk about poverty but it's not that, the most endemic states in Nigeria are not the poorest states. Edo state is an oil producing state for example and so it's a cultural thing, cultural - not traditional, sociocultural. Everybody now knows it is evil so you find people [traffickers] who are doing it who are criminals who know what they have to gain, who are willing to do whatever they have to do... so they try to convince them so you can see greed is playing a central role than ignorance.
\end{abstract}

The idea that greed rather than necessity was a key factor in driving human trafficking was expressed by several rescue service industry stakeholders. Both Johnson and Damilare fail to acknowledge that for our participants it is often not a desire to get rich quick, but a desire to economically survive that driving their involvement. They seem reflexively unaware of the oppression caused by the failing neoliberal capitalist economy in contemporary Nigeria. Damilare adopts a judgemental tone that stigmatises trafficked persons as greedy and 
immoral. This marginalisation of the voice of survivors, and failure to consider the economic, gender and cultural issues influencing human trafficking, does not align with a traumainformed approach (Poole and Greaves, 2012).

These concerns about the moralistic and stigmatic judgements of those providing human trafficking rescue services, and insensitivities to intersections of class and gender, are further illustrated by the opinions of Rotimi the male psychologist and counsellor working at the shelter in Lagos.

In my experience as a psychologist and counsellor of trafficking survivors, it's not poverty that is the cause of trafficking. The number one cause is greed. My father is not rich. As I'm talking to you, my father was not a rich man, I'm not from a rich family and we're seven, I have four sisters, I'm the last born and we struggled but none of my sisters were trafficked. I was not trafficked. So, all these girls you're seeing, it's greed. It's greed that leads them to it. Poverty is just part of it but poverty is not the main cause, it's greed. They want shortcut to success, that's why some of them have fallen victims.

Rotimi is a provider of crucial to survivors. But his beliefs do not instil confidence that a transformative service approach is being adopted by him. Rotimi comments appear to not acknowledge the intersectional drivers of human trafficking, nor do his words suggest that he attached importance to recognising and responding to trauma (Elliott et al., 2005) and relieving suffering (Nasr and Fisk, 2019).

In common with many of our interviewees, consenting to be trafficked for sex work was for Ejiro, a 24-year-old Urhobo woman, an economic choice she made for the sake of her 
family, and she believed it a much better alternative than unemployment. Her entry into the trafficking system however is also shaped by cultural forces. Ejiro recounted how she sought to escape poverty in Nigeria and voluntarily signed an agreement with a madam to be trafficked to Dubai. Ejiro had dropped out of high school in second year to care for her family. Trauma affected the atmosphere as she was telling her story, her voice was breaking with sadness as she slumped her shoulders and looked down while she explained that her mother had died and that her father was absent, giving her full responsibility for her younger siblings' care and welfare. Her low socio-economic status, lack of education, and the lack of social welfare in contemporary capitalist Nigeria made her vulnerable to being trafficked. At the same time, cultural beliefs shaped her commitment to fulfilling the conditions of her bondage:

My ex-boyfriend told me that there's a girl that is looking to take people to Dubai. He asked me if I wanted to travel and I said yes. He gave me the number of the girl and I called her. The girl and I then agreed to meet. She asked me if I wanted to go to Dubai and I said yes. We had an agreement that if I reached Dubai that I will pay her money before I start working on my own. She charged me \$USD15,000. I said ok no problem I will pay you. I started paying her when I got there. I told my madam nothing will make me run away because I don't want the oath to affect me...I didn't really believe in the oath but there are many people that die on it, people that make the agreement and then they come to Dubai and they don't pay the boss...I told my madam that as long as I have made up my mind to make an agreement with you I will come to Dubai and nothing will make me run...I will you give you your money, then I will continue with my own. 
That Ejiro's ex-boyfriend would consider her willing to be trafficked to escape destitution illustrates the objectification of women in modern Nigeria. Her experience in being forced to take an oath during a juju ritual also shows how human traffickers have commandeered powerful traditional spiritual beliefs that still hold significant importance in Nigeria (Oluwọlé, 1997), and have fused these with a contemporary desire for material wealth and status (Oyéwumi, 1997), to oppress her. As Emmanuel who worked in Abuja as the Head of Research and Planning with a Government Human Trafficking Agency explained, the juju oaths hold a psychological spell over people:

It's a very psychological thing, they [traffickers] have to have a lot of skill, and you have to get them to the point of understanding. It is when they [survivors] understand that their eyes are open, and we can free them from oaths.

Ejiro shared her experience with the bitterness of someone who had been empowered to take control of her life but was now left powerless. Human trafficking becomes positioned in her and other participants' narratives as providing emancipatory potential - an opportunity for employment, migration into a more urbanised and cosmopolitan lifestyle, and consequently freedom from oppressive economic conditions. As noted above, the effects of an oath grounded in traditional culture and spiritual beliefs worked to hold Ejiro in a bond with her traffickers. This aligns with the observations of Hepi et al., (2017) on how traditional cultural beliefs should be acknowledged in TSR contexts.

The experiences of Mbika, a 21-year-old Efik woman, provides an example of how class and gender and trauma intersect in the context of human trafficking. Mbika, described gendered violence in human trafficking as part of her experience. Mbika came from a rural village before being approached to travel to another state in Nigeria for work as a maid. She 
has a young child and was looking for a way to help and financially support herself and her child. Mbika sadly explained how she had been both physically and sexually abused when trafficked.

\begin{abstract}
I followed that man because he promised he had a job. Instead, the man slept with me then he started abusing and beating me. His brother also started abusing and beating me. Look at all these marks on my body... [shows bruises and cuts on her body] It was this that made me report them to civil defence.
\end{abstract}

Mbika's experience points to the oppression of Nigerian women and commodification and objectification of their bodies, and how this leads some such as Mbika to be trafficked, raped, and beaten. Significantly, Mbika's experience in accessing rescue services was also not positive. She believed she was being held in bondage at the rescue shelter, and that the shelter was not sympathetic to her plight as a mother with a young child. Her eyes brimming with tears and her hands clasped tightly together, she fell to her knees and tearfully pleaded with the lead researcher to be released from the shelter so she could find work to support her daughter.

As I am now, I'm not happy. I have cried endlessly. Please let them [the rescue shelter management] pity me. I have a child. She's getting to three years old now. Nobody takes care of her but me... my mother can't afford to take care of my child.... I just wanted to get a little bit of money then find a small business to do to help my child. I'm the only one taking care of my child. Please help me, I beg you. I want to leave here so I can work to help my daughter. 
Mbika's experience draws attention to some of the limitations of the 'rescue industry' to provide trauma-informed services to support, rehabilitate and provide progressive opportunities to trafficked women (Elliott et al., 2005; Poole and Greaves, 2012).

While poor economic position and the hope of economic empowerment is widely evident as a motivation for our interviewees, not all interviewees experienced even this level of agency in being trafficked as demonstrated by Osas a 24-year-old Bini woman who lived at home with her mother prior to being trafficked. She did have some education and went to high school but was forced to drop out in her last year due to an inability to afford the school fees. This led to her being in a poor economic position.

\begin{abstract}
My friends approached about going to work in Dubai. She said I will be working as a house maid in Dubai with a wealthy family. I said ok and I asked my mum and she also agreed. But when I got to Dubai my madam seized my passport and forced me into doing prostitution. In Dubai they made me promise to pay back $\$ 16,000$. I had nobody there to help me, so I reported myself to the police in Dubai and the deported me back to Nigeria and then I was brought here. I was there for four months working as a prostitute.
\end{abstract}

For Osas, being deceived means that her experience cannot align with the rational economic choice discourse in the human trafficking literature (see O'Brien et al., 2013). However, she did use agency in reporting herself to the authorities to escape prostitution. The trafficking experience was clearly damaging for Osas. Despite receiving some support such as counselling at the rescue shelter, she said: "Honestly I just want to go home. I don't want to press charges against anybody. I just want to go home”. Osas's distress was apparent with her arms tightly folded across her chest, and she was reluctant to share details 
of her experience in Dubai. Osas's experiences and her desire to leave the shelter again raised questions about whether the services provided for survivors are giving voice to women and acknowledging the complex intersectional drivers of human trafficking. This provides further impetus for the adoption of an intersectionality (Corus and Saatcioglu, 2015) and traumainformed approach (Elliott et al., 2005) to transformative services to address human trafficking (Loomba, 2017).

\section{Discussion}

\section{Theoretical Implications}

\section{Conceptualising TSR through being intersectionality and trauma informed}

Our discussion engages with the conceptual, contextual, and practical implications that emerge from our research and identifies areas for future research. The experiences of interviewed trafficked women narrated here indicate that integrating understandings of intersectionality (Corus and Saatcioglu, 2015), and trauma (Elliott et al., 2005) in TSR is imperative. These key concepts of intersectionality and being trauma-informed should be accounted for in transformative services theory, research, and practice where at all relevant. Building upon African feminist perspectives on intersectionality (Imam, 2016) we argue that the theorising, design and delivery of transformative services in contexts such as human trafficking should acknowledge how factors such as class, gender and culture intersect; and how the trauma experienced by survivors - and which extends to the experience of being involuntarily rescued — will affect service interactions, processes, and outcomes. For example, relevant policy and the design and delivery of counselling and rehabilitation services should adopt an intersectional framework and trauma-informed approaches.

Our findings build upon existing research evidence that accounts for how various push factors including poverty, unemployment and inequality (Elabor-Idemudia, 2003; 
Danailova-Trainor and Laczko, 2010); and pull factors including demands for sex and low skilled labour, low-risk and high profitability from trafficking, and the individual desire for a higher quality and more cosmopolitan life help drive human trafficking. We argue that that understanding of human trafficking, and the services and service actors in the system, should acknowledge the context-specific intersections of factors such as class, gender, culture, and trauma. Our empirical focus on Nigeria demonstrates the cultural specificity of experiences, and intersections of socio-economic class, gender, cultural beliefs, and ideologies. Instead of espousing stigmatic ideas that greed is driving people into being trafficked, there needs to be a focus on the low socio-economic status of people such as our research participants that is linked to unemployment, lack of educational opportunities, and the failures of capitalism in Nigeria (Oluwọlé, 2014). Furthermore, there should be recognition of how contemporary oppressive gender dynamics in Nigeria cause Nigerian women to be objectified, commodified and abused - as demonstrated by how some of our participants were introduced or tricked into being trafficked by men known to them, or were physically or sexually abused by clients and handlers.

\section{Rethinking human trafficking discourse}

Our study also highlights the ideological tensions within the human trafficking discourse and the danger of misaligned ideologies in shaping discursive practice. Our participants' stories demonstrate the motivational conflicts they experience, that are framed by class, gender and cultural conditions in Nigeria, and which generates tensions between lack of economic opportunity, the appeal of being trafficking, and the supposed salvation offered by human trafficking rescue services. These complexities are not acknowledged in the discourse emerging from rescue services leadership when contrasted with that of 
survivors. Instead a dangerous victim-blaming discourse emerges that increases survivors' risk of re-traumatisation and re-trafficking.

While we do not deny the agency of survivors, we call for a change to the rescue industry's reductionist discourse, which denies the socio-economic, socio-cultural and sociohistorical forces shaping survivors' lived experiences. We argue that such moralising of survivors' motivation — as based on greed — serves only to reproduce survivors' vulnerability and oppression. This lack of nuance and failure to acknowledge the complexity of the problem of human trafficking, and the diversity of survivors' lived experience, has the potential to reproduce survivor experiences of stigma and trauma as well as undermine their ability to reintegrate successfully into their communities. Our study highlights the risks of maintaining such ideology that is charged to rehabilitate them.

\section{Implications for value creation and destruction, and well-being}

We also identified that the delivery of existing human trafficking rescue services can lead to value destruction and negative outcomes in terms of well-being in the service environment (see Leo and Zainuddin, 2017). As our research findings illustrate, such value destruction may also lead to the possibility that survivors re-enter the human trafficking market system. The TSR literature makes a general assumption that the co-creation of value through the service experience will generally lead to consumer well-being (Anderson et al., 2015). However, in socially unacceptable service contexts such as human trafficking this value is subjective and determined by the individual. Indeed, as evidenced by some of our participants, despite its illegality and risks, human trafficking is deemed to create value-in terms of income and apparent economic empowerment for trafficked women. Thus while being rescued seems to create value and lead to objective well-being in freeing a person from 
the bondage imposed by human trafficking, it may also lead to value destruction and damage to subjective well-being through removing the opportunity to escape from poverty.

In our context, it could be argued that in order to achieve well-being it may not always be possible to create subjective value, and indeed some amount of value destruction is inevitable at least in the short term. However, over the longer term, and assuming that rescue services can successfully rehabilitate and provide pathways to good employment and income earning opportunities, the value destruction at the point of being rescued can become a positive. This is because the value that people desire-economic survival if not empowerment-- is derived from activities that are objectively harmful to them.

Heretofore, TSR research has primarily focused on how resource mis-integration leads to value destruction in service environments (Laud et al., 2019). We argue for a broader focus that acknowledges how macro factors such as neoliberal capitalism, gender, power, traditional beliefs, and sociocultural norms can shape value creation and destruction. It also suggests a need for greater consideration of the balance between objective and subjective well-being, depending on the context. We identify that transformative human trafficking services should carefully consider pathways for the co-creation of value and both subjective well-being that pays careful attention to the influence of macro factors, as well as the alignment of expectations, resources and outcomes (Anderson and Ostrom, 2015).

\section{Practical Implications}

\section{Towards an intersectionality and trauma-informed framework for transformative services}

Our findings also suggest some important implications for policy, practice and future research. We argue that understanding of context-specific intersectionalities, and recognition of the criticality of trauma-informed approaches should be embedded alongside existing understanding of push and pull factors in relevant policy discourse, language and policy 
documents relating to human trafficking prevention and support reintegration. Language must de-emphasise morality and focus more on the socioeconomical and sociocultural drivers of the problem. Doing so can help set the tone in society for recognising that human trafficking is a complex issue that is shaped by intersections of class, gender, ethnicity, culture, and trauma. Policy that acknowledges these factors, can also then mandate specific programs to tackle human trafficking that acknowledge intersectionalities and trauma.

Human trafficking program design principles, strategies and tactics such as social marketing campaigns, education, and advocacy should also address how intersectional dimensions including class, gender, ethnicity, culture and trauma shape the problem, the lived experiences of, and support the needs of survivors. We also identify that there is a need to represent intersectionalities and trauma in terms of the people featured in human trafficking programs such as social marketing, education and advocacy - as well as those who work for human trafficking rescue services. This can help dissuade those at risk of trafficking through relatable stories about the social determinants, realities and consequences of human trafficking from bona fide survivors. Furthermore, paying survivors to tell their stories in campaigns can also serve to empower them and provide them with employment opportunities. Such representation could facilitate stronger understanding and better representation of the issues, as well as facilitating higher levels of trust with survivors.

We propose a context-specific intersectional and trauma-informed framework for transformative services (see Figure 1) to guide work with vulnerable populations in global south contexts for sustained impact. We theorise that rescue services informed by this framework may reduce survivors' experiences of trauma and stigmatisation on return to their community, reduce their vulnerability to re-trafficking, build their resilience, and offer them opportunities and the ability to reintegrate fully into their community. In our framework, we illustrate how factors such as socioeconomic class, gender, culture and trauma intersect 
alongside various push and pull factors within the human trafficking market system to reproduce vulnerability to trafficking and should inform rescue services.

\section{INSERT FIGURE 1 HERE}

Our framework integrates these key constructs with a process to inform the design and delivery of context-specific intersectionality and trauma-informed transformative services. Working from this framework we propose a critical and reflexive approach to transforming the rescue services industry that honours the complexities of survivors' lived experiences, and acknowledges the social environment that shapes their vulnerabilities, alongside the problematic rescue services structures, processes and practices that reproduce and perpetuate these vulnerabilities. The conceptualisation, design and delivery of such services could also integrate value co-design processes, to facilitate an intersectionality and trauma-informed approach to human trafficking rescue services that empowers survivors.

We advocate the use of our framework to inform already existing human trafficking rescue service activities such as counselling and rehabilitation, employment and entrepreneurship skills training, and financial literacy courses. Furthermore, the framework can also inform more critically reflexive awareness and advocacy in recognition of oppressive socioeconomic conditions. The provision of critical education and cultural learning about traditional gender, culture and spiritual beliefs could also be beneficial. Such educational interventions should emphasise not only push and pull factors, but also the intersectionalities that increase susceptibility to trafficking. Finally, we submit that the adoption of traumainformed principles to acknowledge the impact of trauma, understand pathways for recovery, recognise signs and symptoms of trauma among survivors, fully integrates knowledge about trauma into service policies, procedures, and practices; and actively seeks to resist re- 
traumatisation are critical (Rubenstein et al., 2018). While some of these services are already provided by the human trafficking rescue industry, we are calling for a more critically informed, reflexive and holistic approach that accounts for intersectionalities and trauma.

\section{Conclusion}

Our context of Nigeria may not be representative of the global rescue services industry or indeed representative of the global south context. This paper however has introduced the importance of context specific interrogations. Future research could pilot and evaluate our proposed context-specific (e.g. African) intersectional framework to the design and delivery of human trafficking rescue services in Nigeria. Finally, future TSR research that enriches emic understandings of how intersectionality affects issues such as domestic violence, and gender equality in countries such as Indonesia or India would be welcomed (e.g. Martam, 2016). Such work would not only help to generate insights for theory research and practice, but would also help to further decolonise the extant literatures in TSR, and on intersectionality, that are currently dominated by Western perspectives that may not be appropriate for Global South contexts.

\section{References}

Abegunde, O., Akinyemi, T.E. (2014). Public Policy, Welfarism, and Social Service Delivery in Nigeria: The Case of a Receeding State. Journal of Law, Policy and Globalization, 22: 134-144.

Adler, P. A. and Adler P. (2012) in ' How many qualitative interviews is enough? Expert voices and early career reflections on sampling and cases in qualitative research' Eds Baker, S.E and Edwards R. National Centre for Research Methods. p 8. 
Ampofo, A. A., Beoku-Betts, J., Njambi, W. N., \& Osirim, M. (2004). Women's and Gender Studies in English-Speaking Sub-Saharan Africa: A Review of Research in the Social Sciences. Gender \& Society, 18(6), 685-714.

Anderson, L., \& Ostrom, A. L. (2015). Transformative Service Research: Advancing Our Knowledge About Service and Well-Being. Journal of Service Research, 18(3), 243-249. Anderson, L., Ostrom, A. L., \& Bitner, M. J. (2011). Surrounded by services: A new lens for examining the influence of services as social structures on well-being. Working paper. W. P. Carey School of Business, Arizona State University.

Argyris, C. (1982). Reasoning, learning, and action: Individual and organizational (pp. 85101). San Francisco, CA: Jossey-Bass.

Askegaard, S., \& Linnet, J. T. (2011). Towards an epistemology of consumer culture theory: Phenomenology and the context of context. Marketing Theory, 11(4): 381-404.

Atong, K., Mayah, E., Odigie, A. (2018). Africa Labour Migration To The GCC States: The Case of Ghana, Kenya, Nigeria And Uganda. Lome: African Regional Organisation of the International Trade Union Confederation.

Baarda, C.S. (2016). Human trafficking for sexual exploitation from Nigeria into Western Europe: The role of voodoo rituals in the functioning of a criminal network. European Journal of Crimonology, 13(2): 257-273.

Badéjọ, F., Rundle-Thiele, S. and Kubacki, K. (2019). Taking a wider view: A formative multi-stream social marketing approach to understanding human trafficking as a social issue in Nigeria, Journal of Social Marketing, 9(4): 467-484.

Berliner, L., \& Kolko, D. J. (2016). Trauma Informed Care: A Commentary and Critique. Child Maltreatment, 21(2), 168-172.

Bryant, A., Charmaz, K. (2007). The SAGE Handbook of Grounded Theory. London: Sage. 
Cheung, L. and McColl-Kennedy, J. (2019), "Addressing vulnerability: what role does marketing play?", Journal of Services Marketing, 33(6): 660-670.

Cheung, L., McColl-Kennedy, J.R. and Coote, L.V. (2017), "Consumer-citizens mobilizing social capital following a natural disaster: effects on well-being", Journal of Services Marketing, Vol. 31 No. 4/5, pp. 438-451.

Corus, C. and Saatcioglu, B. (2015). An intersectionality framework for transformative services research, The Service Industries Journal, 35:7-8): 415-429.

Crenshaw, K (1989). Demarginalizing the Intersection of Race and Sex: A Black Feminist Critique of Antidiscrimination Doctrine, Feminist Theory and Antiracist Politics. University of Chicago Legal Forum, 1989(1): 139-167.

Crenshaw, K. (2019). On Intersectionality: The Essential Writings of Kimberlé Crenshaw. New York: The New Press.

Czarniawska, B. (2004). Narratives in social science research. London: Sage.

Danaher, T. S., \& Gallan, A. S. (2016). Service Research in Health Care: Positively Impacting Lives. Journal of Service Research, 19(4), 433-437.

Danailova-Trainor, G., Laczko, F. (2010). Trafficking in persons and development: towards greater policy coherence. International Migration, 48(4): 38-83.

Davis, A. (1981). Women, Race and Class. New York: Ballantine Books.

Dietrich, T., Trischler, J., Schuster, L. and Rundle-Thiele, S. (2017), "Co-designing services with vulnerable consumers", Journal of Service Theory and Practice, Vol. 27 No. 3, pp. 663-688.

Egharevba, M.E., Imhonopi, D., Iruonagbe, C.T. (2015). Neoliberal reforms, healthcare and other human development challenges in Nigeria. Global Journal of Human Social Science, 15(2): $1-10$. 
Elabor-Idemudia, P. (2003). Race and Gender Analyses of Trafficking: A Case Study of Nigeria. Canadian Woman Studies, 22(3): 116-123.

Ekanade, O.V. (2014). The dynamics of forced neoliberalism in Nigeria since the 1980s. Journal of Retracting Africa, 1(1): 1-24.

Elliott, D.E., Bjelajac, P., Fallot, R.D., Markoff, L.S., Glover Reed, B. (2005).

Trauma-informed or trauma-denied: Principles and implementation of trauma-informed services for women. Journal of Community Psychology, 33(4): 461-477.

Fisk, R.P., Dean, A.M., Alkire (née Nasr), L., Joubert, A., Previte, J., Robertson, N. and Rosenbaum, M.S. (2018), "Design for service inclusion: creating inclusive service systems by 2050", Journal of Service Management, Vol. 29 No. 5, pp. 834-858.

Funston, L. (2019). In the business of trauma: an intersectional-materialist feminist analysis of 'trauma informed' women's refuges and crisis accommodation services in Sydney and Vancouver. PhD Thesis, University of Sydney.

Gay, D., Hatton, D. (2000). Accessing vulnerable populations for research. Western Journal of Nursing Research, 22(2): 244-251.

Giesler, M. and Thompson, C.J. (2016) 'A Tutorial in Consumer Research: Process Theorization in Cultural Consumer Research', Journal of Consumer Research 43(4): 497508 .

Hepi, M., Foote, J., Finsterwalder, J., Moana-o-Hinerangi, M.-o., Carswell, S. and Baker, V. (2017), "An integrative transformative service framework to improve engagement in a social service ecosystem: the case of He Waka Tapu", Journal of Services Marketing, Vol. 31 No. 4/5, pp. 423-437.

Ibezim-Ohaeri, V. (2018). Nigeria. In Akhami, M., Ertürk, Y., Mayer, A.E (Eds.) Feminist Advocacy, Family Law and Violence against Women. London: Routledge. 
Ikeora, M. (2016). The Role of African Traditional Religion and 'Juju' in Human Trafficking: Implications for Anti-trafficking. Journal of International Women's Studies, 17(1), 1-18. Imam, A. (2016). The Devil is in the Details: At the Nexus of Development, Women's Rights, and Religious Fundamentalisms. Toronto: Association for Women's Right in Development.

International Labour Organization [ILO]. (2017). Forced labour, modern slavery and human trafficking. Geneva: ILO.

Jeffries, S. (1997). The Idea of Prostitution. Melbourne: Spinifex Press.

Kabadayi, S. (2019), "Understanding employee sabotage while serving refugees: the case of Syrian refugees in Turkey", Journal of Services Marketing, Vol. 33 No. 7, pp. 946-958.

Kvale, S. (1983). The qualitative research interview: A phenomenological and a hermeneutical mode of understanding. Journal of phenomenological psychology, 14(2), 171-196.

Laud, G., Bove, L., Ranaweera, C., Leo, W.W.C., Sweeney, J. and Smith, S. (2019), "Value co-destruction: a typology of resource misintegration manifestations", Journal of Services Marketing, Vol. 33 No. 7, pp. 866-889,

Leo, C. and Zainuddin, N. (2017), "Exploring value destruction in social marketing services", Journal of Social Marketing, Vol. 7 No. 4, pp. 405-422.

Loomba, A.P.S. (2017). Reconstructing lives: transformative services for human trafficking survivors", Journal of Services Marketing, Vol. 31 No. 4/5, pp. 373-384.

Mackay, F. (2014). Book Review: The politics of sex trafficking: A moral geography. Women's Studies International Forum, 44: 203-204.

Macdonald, C, Merrill, D (2009) Intersectionality in the emotional proletariat: a new lens on employment discrimination in service work. In: Korczynski, M, Macdonald, C (eds) Service Work: Critical Perspectives. New York, NY: Routledge, 113-35. 
McCall, L. (2005). The complexity of intersectionality. Signs: Journal of Women in Culture and Society, 30(3), 1771-1800.

Madunagu, B.E. (2008) The Nigerian Feminist Movement: Lessons from Women in Nigeria, WIN. Review of African Political Economy, 35(118): 666-673.

Martam, I. (2016). Commentary: Strategic social marketing to foster gender equality in Indonesia. Journal of Marketing Management, 32, 1174-1182.

Minderoo Foundation's Walk Free Initiative. (2018). Global Slavery Index. Perth, W.A: Minderoo Foundation's Walk Free Initiative.

Mende, M., \& van Doorn, J. (2015). Coproduction of Transformative Services as a Pathway to Improved Consumer Well-Being: Findings From a Longitudinal Study on Financial Counseling. Journal of Service Research, 18(3), 351-368.

Nasr, L., and Fisk, R. (2019) The global refugee crisis: how can transformative service researchers help?, The Service Industries Journal, 39:9-10, 684-700.

O'Brien, E., Hayes, S., Carpenter, B. (2013). The politics of sex trafficking: A moral geography. London: Palgrave Macmillan.

Oke, O., Lanre-Babalola, F., Tom, R. (2018). Correlates of the Psychosocial Wellbeing of Human Trafficking Survivors in Lagos State, Nigeria. African Journal for The Psychological Studies of Social Issues, 21(3), 193-203.

Okpanachi, E., Obutte, P.C. (2015). Neoliberal Reforms in an Emerging Democracy: The Case of the Privatization of Public Enterprises in Nigeria, 1999-2014. Poverty \& Public Poverty, 7(3): 253-276.

Ogundipe, O. (1994). Re-creating ourselves: African women and critical transformations. Trenton, N.J: Africa World Press.

Omorodion, F. I. (2009). Vulnerability of Nigerian Secondary School to Human Sex Trafficking in Nigeria. African Journal of Reproductive Health, 13(2). 
Oluwọlé, S. (1997). Philosophy and oral tradition. Lagos: Ark Publishers.

Oluwọlé, S. (2014). African myths and legends of gender. Lagos: Ark Publishers.

Osezua, O.C. (2011). Cross-border sex trade, transnational remittances and changing family structures among Benin people of Southern Nigeria. Gender \& Behaviour, 9(2): 42764297.

Oyéwumi, O. (1997). The Invention of Women: Making an African Sense of Western Gender Discourses. Minnesota: University of Minnesota Press.

Pennington, J. R., Ball, A. D., Hampton, R. D., \& Soulakova, J. N. (2009). The cross-national market in human beings. Journal of Macromarketing, 29(2), 119-134.

Pink S, Morgan J (2013) Short-term ethnography: Intense routes to knowing. Symbolic Interaction 36(3): 351-361.

Poole, N., and Greaves, L. (2012). Becoming Trauma Informed. Toronto: Centre for Addiction and Mental Health.

Rosenbaum, M.S., Ward, J., Walker, B.A. and Ostrom, A.L. (2007), “A cup of coffee with a dash of love: an investigation of commercial social support and third-place attachment", Journal of Service Research, Vol. 10 No. 1, pp. 43-59.

Rosenbaum, M. S., Corus, C., Ostrom, A. L., Anderson, L., Fisk, R. P., Gallan, A. S., Williams, J. D. (2011). Conceptualisation and aspirations of transformative service research. Journal of Research for Consumers, 19, 1-6.

Rosenbaum, M.S., Seger-Guttmann, T. and Mimran, O. (2018), "The role of social incompatibility in customer discomfort", Journal of Service Management, Vol. 31 No. 4, pp. $815-837$.

Rubenstein, L., Dukes, S., Fearing, C., Foster, B. K., Painter, K., Rosenblatt, A., \& Rubin, W. (2018). A Case Study for Social Marketing: Key Strategies for Transforming the 
Children's Mental Health System in the United States. Social Marketing Quarterly, 24(3), $132-150$.

Thompson, C. J., Locander, W. B., \& Pollio, H. R. (1989). Putting consumer experience back into consumer research: the philosophy and method of existential phenomenology. Journal of Consumer Research, 133-146.

Tomazelli, J., Broilo, P.L., Espartel, L.B. and Basso, K. (2017), "The effects of store environment elements on customer-to-customer interactions involving older shoppers", Journal of Services Marketing, Vol. 31 No. 4/5, pp. 339-350.

United Nations Office on Drugs and Crime [UNODC] (2018). Global report on trafficking in persons. UNODC: Vienna.

Valadier, C. (2018). Migration and Sex Work through a Gender Perspective. Contexto Internacional, 40(3), 501-524.

von Koskull, C. (2020), "Increasing rigor and relevance in service research through ethnography", Journal of Services Marketing, Vol. 34 No. 1, pp. 74-77.

Wu, L., Han, R. and Mattila, A.S. (2016), "A double whammy effect of ethnicity and gender on consumer responses to management level service failures", Journal of Service Management, 27 No. 3, pp. 339-359.

Zainuddin, N., Gordon, R. (2020). Value creation and value destruction in social marketing services: A review and research agenda. Journal of Services Marketing, 34(3): 347-361. 
Table Ia: Human trafficking survivors interview participants

\begin{tabular}{|c|c|c|c|c|}
\hline Pseudonym & Sex & Age & \multicolumn{2}{|c|}{ Background } \\
\hline Chika & Female & 27 & \multicolumn{2}{|c|}{$\begin{array}{l}\text { Unemployed; uneducated; lived at home with her family, upon whom she was dependent before being } \\
\text { trafficked }\end{array}$} \\
\hline Osas & Female & 24 & \multicolumn{2}{|c|}{$\begin{array}{l}\text { Lived at home with her mother. Attended school but dropped out in her last year of high school due to } \\
\text { inability to afford fees }\end{array}$} \\
\hline Itohan & Female & 28 & \multicolumn{2}{|c|}{$\begin{array}{l}\text { A friend had told her about an "opportunity" to travel for work. Her mother was absent and consequently } \\
\text { unaware of when she was trafficked }\end{array}$} \\
\hline Ejiro & Female & 24 & \multicolumn{2}{|c|}{$\begin{array}{l}\text { Dropped out school during her second year of high school to care for family; absent father, deceased } \\
\text { mother; sole responsibility for her younger siblings }\end{array}$} \\
\hline Isoken & Female & 23 & \multicolumn{2}{|c|}{$\begin{array}{l}\text { From a family of five; Deceased mother and father; sole responsibility for her younger siblings. Dropped } \\
\text { out of school in grade six. Was a hairdresser prior to being approached by her Aunty to travel overseas for } \\
\text { work }\end{array}$} \\
\hline Ukeme & Female & 19 & \multicolumn{2}{|c|}{$\begin{array}{l}\text { Lived and worked in her rural village before being approached to travel to another state to work as a maid. } \\
\text { Travelled for work alongside participants } 7 \text { and } 8\end{array}$} \\
\hline Ayamma & Female & 20 & \multicolumn{2}{|c|}{ Lived in her rural village before being approached to travel to another state for work as a maid. } \\
\hline Mbika & Female & 21 & \multicolumn{2}{|c|}{$\begin{array}{l}\text { Lived in her rural village before being approached to travel to another state for work as a maid. Has a young } \\
\text { child; Was looking for a way to help herself and her child }\end{array}$} \\
\hline Idara & Female & 17 & \multicolumn{2}{|c|}{$\begin{array}{l}\text { Orphaned; dropped out high school after she met a woman who promised her a job and education in the } \\
\text { metropolitan city of Lagos }\end{array}$} \\
\hline Iziegbe & Female & 24 & \multicolumn{2}{|c|}{$\begin{array}{l}\text { Was an apprentice in her hometown; approached by her brother's friend to travel to the metropolitan city of } \\
\text { Lagos to work as a shopkeeper }\end{array}$} \\
\hline \multicolumn{5}{|c|}{ lder Interview Par } \\
\hline \multicolumn{3}{|l|}{ Pseudonym } & Gender & Role \\
\hline \multicolumn{3}{|l|}{ Damilare } & Male & Regional Head \\
\hline \multicolumn{3}{|l|}{ Yemisi } & Female & Regional Head of Public Enlightenment \\
\hline \multicolumn{3}{|l|}{ Rotimi } & Male & Shelter Psychologist \& Counsellor \\
\hline \multicolumn{3}{|l|}{ Emmanuel } & Male & Head of Research \& Program Development \\
\hline \multicolumn{3}{|l|}{ Efe } & Female & National Head of Public Enlightenment \\
\hline \multicolumn{3}{|l|}{ Blessing } & Female & Media \& communications Manager \\
\hline \multicolumn{3}{|l|}{ Johnson } & Male & Project Coordinator \\
\hline
\end{tabular}




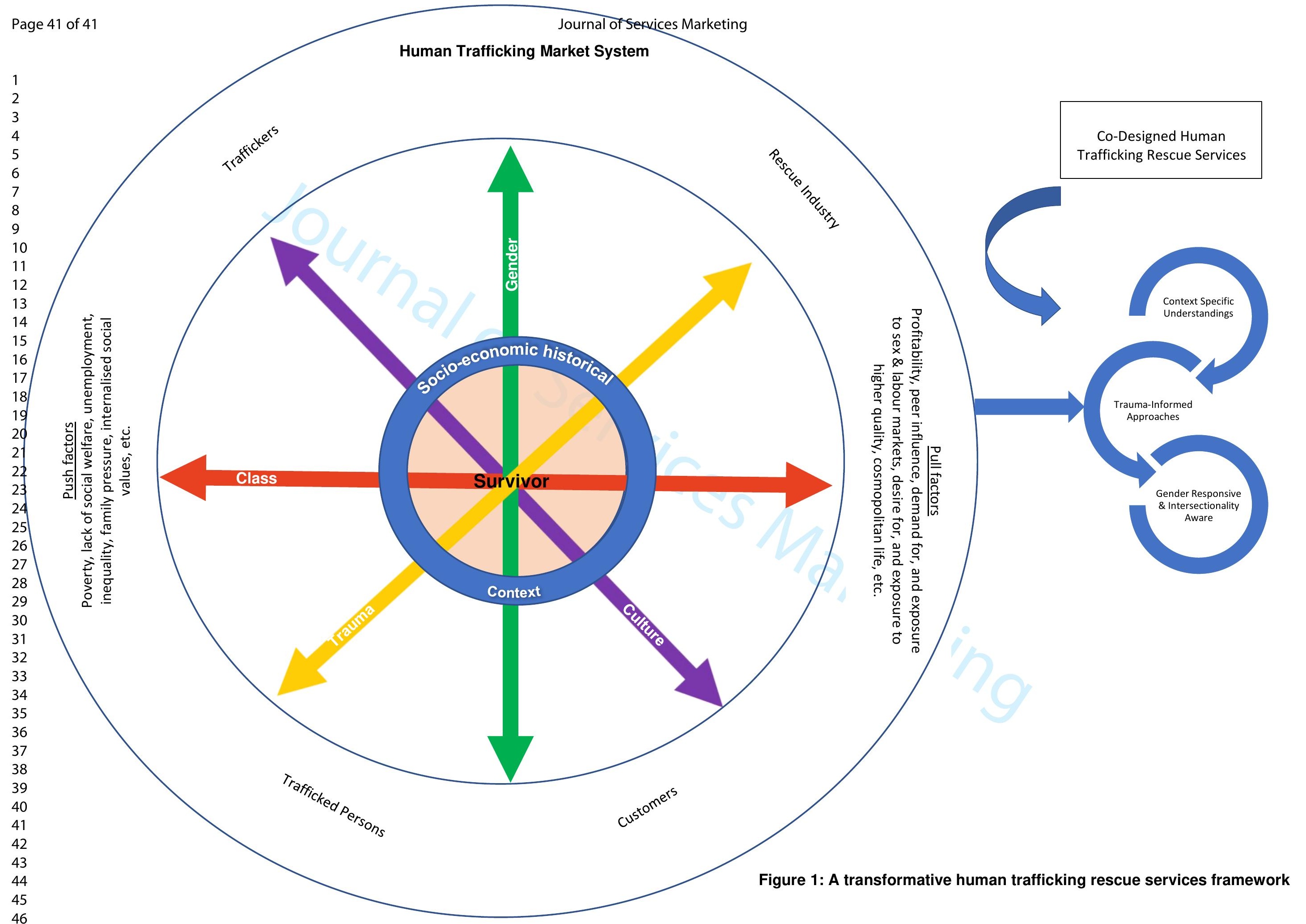

